\title{
In vitro proportional investigation of different Pantoprazole sodium brands of gastro-resistant tablets
}

\author{
Hindustan Abdul Ahad*, Chinthaginjala Haranath, Rahul Raghav Dasari, Madana Gowthami, \\ Naga Jyothi Varam, Pandyala Sravanthi \\ Dept. of Industrial Pharmacy, Raghavendra Institute of Pharmaceutical Education and Research (RIPER) - Autonomous, \\ Ananthapuramu 515721, Andhra Pradesh, India \\ Corresponding author: abdulhindustan@gmail.com
}

\begin{abstract}
The present work is a comparative exploration of some of the physicochemical possessions like weight change, thickness, diameter, hardness, disintegration time, in vitro drug discharge, and analysis studies of various commercially available Pantoprazole sodium tablets (PST) containing $40 \mathrm{mg}$ of drug. The hardness, loss on friability, dissolution test, disintegration test, and uniformity of drug content were evaluated. All the brands meet the requirements as per the pharmacopoeial standards. The dissolution profile study revealed that PST-1 was faster, while PST-2 was slower. The dissolution information was kinetically treated.
\end{abstract}

Keywords: Brand; evolution; kinetics; Pantoprazole.

\section{Introduction}

Gastric passage and $\mathrm{pH}$ outlines are important factors for predicting and controlling drug discharge recital of enteric-coated tablets (ECT). Proton pump inhibitors (PPIs) are widely prescribed for the controlling of the peptic ulcer (Tirpude \& Puranik, 2011), gastro esophageal reflux disorder (GERD), and Zollinger-Ellison syndrome (Mishra et al., 2011). PPIs overwhelm gastric acid secreted by constraining the pumping of the proton $(\mathrm{H}+)$. Entericcoated tablets bypass the stomach with its acid-resistant coating and discharges in intestinal alkaline $\mathrm{pH}$ (Thomson et al., 2010). The ECT of Pantoprazole Sodium (PS) allows drugs through the stomach into the intestine for healthier dissolution and absorption and for avoiding the irritating effect on the gastric mucosa for greater patient compliance (Fukui et al., 2000). Generic drugs have lesser expansion costs; therefore, they are low-priced compared to the original innovative formulations. Although generic drugs encompass similar active ingredients, they have shown differences in quality and efficacy due to differences in formulation techniques and excipients used. The Indian market is augmented with various generic brands of PS (40 mg) gastro-resistant tablets. The objective of this exploration was to evaluate and compare the quality of dissimilar marques of PS $40 \mathrm{mg}$ ECT available in India.

\section{Materials and methods}

2.1. Materials

Resources necessary in this study are listed in table 1.

Table 1. Resources essential in this assessment and source.

\begin{tabular}{ll}
\hline $\begin{array}{l}\text { Pantoprazole sodium-40 } \\
\text { Enteric-coated tablet brands }\end{array}$ & Manufacturer \\
\hline PEPGERD (PST-1) & Sigman \\
PANTOSEC (PST-2) & Cipla \\
PANTODAC (PST-3) & Zydus Cadila \\
PROTONIX (PST-4) & Pfizer \\
PRAZOTO (PST-5) & Solace \\
PANTOP (PST-6) & Aristo \\
\hline Name of the Chemical & Supplier \\
\hline Phosphate buffer solution (pH 6.8) & Lab made \\
Pantoprazole sodium (pure sample) & Walkman Selman \\
& Pharmaceuticals, Pvt. \\
& Ltd., Anantapur \\
\hline Name of the instrument & Made \\
\hline Digital weighing balance & Shimadzu ELB 300 \\
Monsanto hardness tester & Labotech \\
Roche friabilator & HMK Tablet 1601 \\
Disintegration device & Lab India (DT-2901) \\
USP-II dissolution test device & Lab India (DS-8000) \\
\hline
\end{tabular}




\subsection{Methods}

Various brands were considered for the official and unofficial tests as declared below (Ahad et al., 2010; Liberman and Lachman 1991; Reddy et al., 2011; Hindustan et al., 2012).

\subsubsection{Weight uniformity}

The test was achieved by weighing twenty tablets individually, and its mean weight was calculated. The weight deviation percentage of each tablet was calculated to the mean weight. The test results were found satisfactory as the deviation in weight is within the limits $( \pm 5 \%)$ as specified in Indian Pharmacopoeia.

\subsubsection{Thickness}

The thickness of the PST was calculated with Vernier digital calibrators, and mean values were premeditated.

\subsubsection{Hardness}

The tablet to be tested was detained amid a static jaw and a cell phone by Monsanto Hardness Tester. The mean understandings were intended and expressed in $\mathrm{kg} / \mathrm{cm}^{2}$.

\subsubsection{Friability}

The friability test can be accomplished to assess the ability of the tablets to withstand abrasion in packaging, handling, and transport. Preweighed tablets were positioned in the rotation compartment and revolved for $4 \mathrm{~min}$ (100 rpm). Acceptable weight loss limits should not exceed 1\%. The loss in friability was calculated using the formula

$\%$ friability $=\frac{\text { Weight Final }}{\text { Weight Initial }} \times 100$

\subsubsection{Disintegration time}

The disintegration tests of the enteric-coated PS tablets were done by the USP disintegration apparatus. A tablet has been inserted into each tube of the basket frame assembly without a disc. The group was placed in the beaker containing $0.1 \mathrm{~N} \mathrm{HC1} \mathrm{(pH} \mathrm{1.2),} \mathrm{maintained} \mathrm{at}$ $37 \pm 2{ }^{\circ} \mathrm{C}$, and operated for $2 \mathrm{~h}$. After $2 \mathrm{~h}, \mathrm{HC} 10.1 \mathrm{~N}$ was replaced with a phosphate buffer of $\mathrm{pH}$ 6.8. One disc was kept in each tube and run for another $60 \mathrm{~min}$. Then, the disintegration time of each tablet was recorded (Alsulays et al., 2017).

\subsubsection{Dissolution study}

The dissolution test was accepted in two phases in the dissolution apparatus of the type II USP. In the initial step, the setup was performed in a buffer of $\mathrm{pH} 1.2(0.1$ $\mathrm{N} \mathrm{HCl}$ ) at $100 \mathrm{rpm}$ for $2 \mathrm{~h}$. Subsequently, it was moved to the phosphate buffer at $\mathrm{pH} 6.8$, and the dissolution was carried out for $60 \mathrm{~min}$ at $100 \mathrm{rpm}$. The samples were withdrawn on each $5 \mathrm{~min}$ and analysed by UV spectrophotometer using the phosphate buffer as a solution (Haritha, 2017).

\subsubsection{Uniformity of content test}

5 tablets were accurately weighed and minced into a powder. The powder equivalent to $40 \mathrm{mg}$ of PS was carefully weighed and solubilized in about $40 \mathrm{ml}$ of ethanol. $1 \mathrm{ml}$ of the sample was taken and diluted to get $10 \mathrm{mg} / \mathrm{ml}$. Absorbance was restrained at $289 \mathrm{~nm}$, and purity was determined (Tribedi et al., 2013).

\section{Results and discussion}

It was found that the weight variation of all brands was $<5 \%$, and all brands approved the test. All brands have shown good resistance to hardness, necessary for safe handling and transport (table 2). The PST-2 presented the extreme hardness, while all the other brands displayed identical hardness. It was established that the loss on the friability of all the brands was $<1 \%$. All the brands of tablets have passed the disintegration test, which indicates that they will disintegrate completely in the intestine in $2 \mathrm{~h}$, without disintegrating in the stomach. All these tenets were itemized in Figure 1, table 2. The whole brands of PST passed the dissolution test as per the Indian Pharmacopoeia. The PST-1 has maximum \% cumulative PS discharge, i.e., 97.84\%, while PST-2 has the least $(90.25 \%)$, and other brands are above the range (table 3; Figure 1). 
Table 2. Physicochemical physiognomies of PS tablets.

\begin{tabular}{lcccccc}
\hline Parameters & PST-1 & PST-2 & PST-3 & PST-4 & PST-5 & PST-6 \\
\hline Weight of the tablet (mg) & $325 \pm 2.89$ & $386 \pm 1.25$ & $370 \pm 2.36$ & $390 \pm 4.25$ & $364 \pm 1.94$ & $351 \pm 0.85$ \\
Thickness (mm) & $5.50 \pm 0.10$ & $5.40 \pm 0.20$ & $5.30 \pm 0.30$ & $5.20 \pm 0.20$ & $5.30 \pm 0.40$ & $5.20 \pm 0.20$ \\
Hardness (kg/cm2) & $7.20 \pm 0.50$ & $9.80 \pm 0.70$ & $6.80 \pm 0.30$ & $7.00 \pm 0.40$ & $5.80 \pm 0.35$ & $8.30 \pm 0.25$ \\
Friability (\%) & $0.58 \pm 0.01$ & $0.36 \pm 0.02$ & $0.44 \pm 0.03$ & $0.54 \pm 0.04$ & $0.18 \pm 0.01$ & $0.22 \pm 0.01$ \\
Drug content (\%) & $97.84 \pm 2.54$ & $90.25 \pm 5.67$ & $91.58 \pm 2.25$ & $96.38 \pm 4.51$ & $95.21 \pm 5.25$ & $94.65 \pm 4.58$ \\
$\begin{array}{l}\text { Disintegration time } \\
\text { a) In 0.1 N HCl (for 1h) }\end{array}$ & $\mathrm{NED}$ & $\mathrm{NED}$ & $\mathrm{NED}$ & $\mathrm{NED}$ & $\mathrm{NED}$ & $\mathrm{NED}$ \\
b) In 6.8 pH (PBS) (for next & $68 \pm 0.10$ & $45 \pm 0.20$ & $62 \pm 0.30$ & $77 \pm 0.20$ & $60 \pm 0.50$ & $58 \pm 0.20$ \\
120 min) & & & & & & \\
\hline
\end{tabular}

NED- No evidence of disintegration; values in mean $\pm \mathrm{SD}$; trails $(\mathrm{n})=3$

Table 3. In vitro drug discharge profile of PST (1-6) in $0.1 \mathrm{~N} \mathrm{HCl}$ for the first $2 \mathrm{~h}$ and $6.8 \mathrm{pH}$ PBS for the next $1 \mathrm{~h}$ at $289 \mathrm{~nm}$

\begin{tabular}{ccccccc}
\hline & \multicolumn{7}{c}{ Cumulative drug release (\%) } \\
\cline { 2 - 7 } Time (min) & PST-1 & PST-2 & PST-3 & PST-4 & PST-5 & PST-6 \\
\hline 0 & $00.00 \pm 0.00$ & $00.00 \pm 0.00$ & $00.00 \pm 0.00$ & $00.00 \pm 0.00$ & $00.00 \pm 0.00$ & $00.00 \pm 0.00$ \\
15 & $00.00 \pm 0.00$ & $00.00 \pm 0.00$ & $00.00 \pm 0.00$ & $00.00 \pm 0.00$ & $00.00 \pm 0.00$ & $00.00 \pm 0.00$ \\
30 & $00.00 \pm 0.00$ & $00.00 \pm 0.00$ & $00.00 \pm 0.00$ & $00.00 \pm 0.00$ & $00.00 \pm 0.00$ & $00.00 \pm 0.00$ \\
45 & $00.00 \pm 0.00$ & $00.00 \pm 0.00$ & $00.00 \pm 0.00$ & $00.00 \pm 0.00$ & $00.00 \pm 0.00$ & $00.00 \pm 0.00$ \\
60 & $00.00 \pm 0.00$ & $00.00 \pm 0.00$ & $00.00 \pm 0.00$ & $00.00 \pm 0.00$ & $00.00 \pm 0.00$ & $00.00 \pm 0.00$ \\
70 & $00.00 \pm 0.00$ & $00.00 \pm 0.00$ & $00.00 \pm 0.00$ & $00.00 \pm 0.00$ & $00.00 \pm 0.00$ & $00.00 \pm 0.00$ \\
80 & $00.00 \pm 0.00$ & $00.00 \pm 0.00$ & $00.00 \pm 0.00$ & $00.00 \pm 0.00$ & $00.00 \pm 0.00$ & $00.00 \pm 0.00$ \\
90 & $00.00 \pm 0.00$ & $00.00 \pm 0.00$ & $00.00 \pm 0.00$ & $00.00 \pm 0.00$ & $00.00 \pm 0.00$ & $00.00 \pm 0.00$ \\
100 & $00.00 \pm 0.00$ & $00.00 \pm 0.00$ & $00.00 \pm 0.00$ & $00.00 \pm 0.00$ & $00.00 \pm 0.00$ & $00.00 \pm 0.00$ \\
110 & $00.00 \pm 0.00$ & $00.00 \pm 0.00$ & $00.00 \pm 0.00$ & $00.00 \pm 0.00$ & $00.00 \pm 0.00$ & $00.00 \pm 0.00$ \\
120 & $00.00 \pm 0.00$ & $00.00 \pm 0.00$ & $00.00 \pm 0.00$ & $00.00 \pm 0.00$ & $00.00 \pm 0.00$ & $00.00 \pm 0.00$ \\
130 & $34.68 \pm 0.91$ & $28.27 \pm 0.65$ & $31.89 \pm 0.54$ & $27.84 \pm 0.54$ & $32.30 \pm 0.77$ & $32.41 \pm 0.34$ \\
140 & $45.27 \pm 0.35$ & $45.33 \pm 0.98$ & $42.34 \pm 0.68$ & $41.37 \pm 0.87$ & $42.86 \pm 0.69$ & $43.20 \pm 0.30$ \\
150 & $68.75 \pm 0.29$ & $54.41 \pm 0.25$ & $59.46 \pm 0.18$ & $55.82 \pm 0.56$ & $61.74 \pm 0.37$ & $65.40 \pm 1.25$ \\
160 & $82.46 \pm 0.39$ & $78.72 \pm 0.75$ & $80.57 \pm 0.52$ & $78.75 \pm 0.30$ & $80.96 \pm 0.58$ & $80.90 \pm 0.85$ \\
170 & $88.67 \pm 0.34$ & $82.76 \pm 0.48$ & $85.78 \pm 0.48$ & $82.48 \pm 0.39$ & $85.32 \pm 0.01$ & $87.52 \pm 0.46$ \\
180 & $97.84 \pm 0.65$ & $90.25 \pm 0.66$ & $92.59 \pm 0.61$ & $93.63 \pm 0.82$ & $95.87 \pm 0.28$ & $94.59 \pm 0.68$ \\
\hline
\end{tabular}




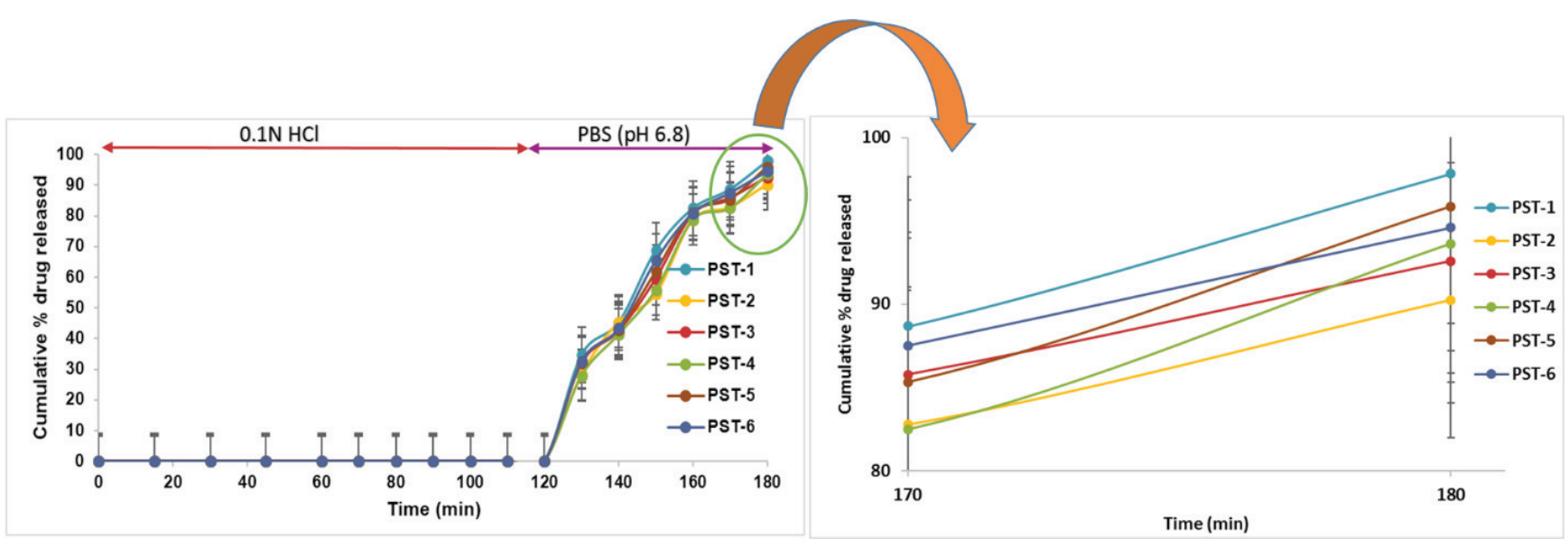

Fig .1. In vitro drug discharge profile of PST; final \% drug released in inset is zoomed.

\section{Conclusion}

All the brands were found to be smooth and elegant in appearance. PS tablets were consistent in diameter, thickness, and weight. PST-1 to PST-6 demonstrated a passable mechanical forte to repel the fracture and erosion. Furthermore, these brands disclosed tolerable disintegration time, PS discharge pattern, and uniformity in PS content. Hence, it was concluded that the swapping among these brands would not affect effectiveness.

\section{ACKNOWLEDGEMENTS}

The authors wish to thank the Walkman Selman Pharmaceuticals, Pvt. Ltd., Anantapur, AP, India, for the gift sample.

\section{References}

Ahad, H.A., Reddy, B.K.K., Ishaq, B.M., Kumar, C.H. \& Kumar, C.S. (2010). Fabrication and in vitro evaluation of glibenclamide Abelmoschus esculentus fruit mucilage controlled release matrix tablets. Journal of Pharmacy research, 3(5), 943-946.

Alsulays, B.B., Kulkarni, V., Alshehri, S.M., Almutairy, B.K., Ashour, E.A. \& Morott, J.T. (2017). Preparation and evaluation of enteric coated tablets of hot-melt extruded Lansoprazole. Drug development and industrial pharmacy, 43(5), 789-796.

Fukui, E., Miyamura, N., Uemura, K. \& Kobayashi, M. (2000). Preparation of enteric coated timed-release press-coated tablets and evaluation of their function by in vitro and in vivo tests for colon targeting. International journal of pharmaceutics, 204(1-2), 7-15.

Haritha, B. (2017). A Review on evaluation of tablets. Journal of Formulation Science \& Bioavailability, 1(1), $1-5$.

Hindustan, A.A., Babu, U.A., Nagesh, K., Kiran, D. S. \& Madhavi, K.B. (2012). Fabrication of glimepiride Datura stramonium leaves mucilage and poly vinyl pyrrolidone sustained release matrix tablets: in vitro evaluation. Kathmandu university journal of science, engineering and technology, 8(1), 63-72.

Liberman H \& Lachman L. (1991). The Theory and Practice of Industrial Pharmacy. 3rd Ed. Bombay: Verghese Publication House, 171-193.

Mishra, C.K., Goyal, A., Sahu, M., Rani, A., Sasmal, D. \& Nema, R.K. (2011). Pantoprazole and its enteric coating polymer concentration for Stable coating in acid media in stomach. IJPCR, 3, 45-47.

Reddy, S.S.P., Ahad, H.A., Sreenivasulu, R., Reddy, B. K.K., Mahesh, C.H.K., Kranthi, G. \& Chandrasekhar, A. (2011). Preparation and evaluation of glipizide Azadirachta indica fruit mucilage Poly Vinyl Pyrrolidone sustained release matrix tablets. Der Pharmacia Lettre, 3(1), 138-144.

Thomson, A.B., Sauve, M.D., Kassam, N. \& Kamitakahara, H. (2010). Safety of the long-term use of proton pump inhibitors. World journal of gastroenterology: WJG, 16(19), 2323. 
Tirpude, R.N. \& Puranik, P.K. (2011). Rabeprazole sodium delayed-release multiparticulates: Effect of enteric coating layers on product performance. Journal of advanced pharmaceutical technology \& research, 2(3), 184.

Tribedi, S., Ananthapur, M., Sabitha, J.S., Mathappan, R. \& Prasanth, V.V. (2013). Formulation and evaluation of enteric coated tablets of Pantoprazole. International Journal of Pharmaceutical and Chemical Sciences, 2(3), 1454-1461.

Submitted : 10/11/2019

Revised : 30/12/2019

Accepted : 16/01/2020

DOI $\quad: 10.48129 /$ kjs.v48i1.8598 